\title{
Cosmetic Reconstruction of Frontotemporal Depression Using Polyethylene Implant after Pterional Craniotomy
}

\author{
Sang Hyuk Im, ${ }^{1}$ Jongkeun Song, ${ }^{2}$ Sang Kyu Park, \\ Eun Young Rha $\left(\mathbb{D},{ }^{2}\right.$ and Young-Min Han $\mathbb{1}^{3}$ \\ ${ }^{1}$ Department of Neurosurgery, College of Medicine, The Catholic University of Korea, Seoul, Republic of Korea \\ ${ }^{2}$ Department of Plastic and Reconstructive Surgery, College of Medicine, The Catholic University of Korea, Seoul, Republic of Korea \\ ${ }^{3}$ Department of Neurosurgery, Naeun Hospital, Incheon, Republic of Korea
}

Correspondence should be addressed to Eun Young Rha; reyrha@catholic.ac.kr and Young-Min Han; hymnsolmh@gmail.com

Received 11 April 2018; Revised 7 September 2018; Accepted 26 September 2018; Published 21 October 2018

Academic Editor: Eberval G. Figueiredo

Copyright (C) 2018 Sang Hyuk Im et al. This is an open access article distributed under the Creative Commons Attribution License, which permits unrestricted use, distribution, and reproduction in any medium, provided the original work is properly cited.

Purpose. Pterional craniotomy is a useful approach for the treatment of a variety of intracranial pathologies. However, it can result in temporal hollowing, which causes significant craniomaxillofacial asymmetry and esthetic deformity. The present study was performed to determine the postoperative outcomes of patients following frontotemporal depression reconstruction using a high-density porous polyethylene (HDPE) implant (Medpor ${ }^{\circledR}$; Stryker, Kalamazoo, MI) after pterional craniotomy. Materials and Methods. The patients had undergone reconstruction of frontotemporal depression using Medpor ${ }^{\circledR}$ implants after pterional craniotomy at our medical institution during the period from February 2010 to March 2014. We evaluated the thickness and volume of both the temporalis muscle and Medpor ${ }^{\circledR}$ implant through a retrospective review of the medical records and computed tomography (CT) scans of 92 patients. Results. The mean temporalis muscle thickness ratio (muscle thickness of the affected side/nonaffected side) was $0.61 \pm 0.16$. The mean reconstructed temporalis muscle thickness ratio (muscle and Medpor ${ }^{\circledR}$ implant thickness of affected side/muscle thickness of nonaffected side) was $1.15 \pm 0.02$. The mean temporalis muscle volume ratio (muscle volume of affected side/nonaffected side) was $0.67 \pm 0.02$. The mean reconstructed temporalis muscle volume ratio (muscle and Medpor ${ }^{\circledR}$ implant volume of affected side/muscle volume of nonaffected side) was $1.18 \pm 0.02$. Conclusions. Temporalis muscle thickness and volume were significantly decreased on the affected side after pterional craniotomy. Reconstruction of frontotemporal lesions using Medpor ${ }^{\circledR}$ implants after the pterional approach improved temporal hollowing without additional complications.

\section{Introduction}

Pterional craniotomy, first described by Yasargil in 1975, is one of the most commonly used techniques in vascular neurosurgery [1-3]. Although this approach enables easy access to a variety of lesions in the anterior and middle cranial fossae, superior aspect of the posterior cranial fossa, sellar and parasellar regions, superior orbital fissure, and cavernous sinus [1,4-7], it has several limitations, such as temporalis muscle atrophy and facial nerve damage, which are matters of great concern to patients even with successful postoperative outcome. Temporal hollowing, that is, contour irregularity in the frontotemporal region, develops due to disruption of the ligamentous attachments among soft tissue and compromised blood supply to the temporoparietal fascia and superficial temporal fascia during dissection of the frontotemporal area [8-12]. This can cause significant esthetic deformity and eventually lead to a decrease in patient compliance in relevant cases.

A number of modified dissection techniques using a pterional approach have been developed to prevent temporal fossa depression and reduce the risk of frontal branch injury. However, there has been debate regarding the effectiveness of methods to achieve both excellent clinical (by ensuring a sufficient visual field) and cosmetic results [13-15]. Moreover, although various autograft and allograft materials have been described for use in reconstruction of temporal hollowing 
[16-20], there have been few studies assessing the cosmetic effects based on objective measurements.

Here, we present our technique involving frontotemporal reconstruction using a high-density porous polyethylene (HDPE) implant (Medpor ${ }^{\circledR}$; Stryker, Kalamazoo, MI) following pterional craniotomy and evaluate the outcomes of temporal augmentation.

\section{Materials and Methods}

2.1. Study Population. In this single-center, retrospective study, we evaluated the medical records and computed tomography (CT) scans of 99 patients who had undergone temporal hollowing reconstruction using Medpor ${ }^{\circledR}$ temporal implants after pterional craniotomy at Incheon St. Mary's Hospital between February 2010 and March 2014.

Inclusion criteria for the present study were as follows:

(1) Patients diagnosed with unruptured aneurysms without neurological deficits

(2) Patients who underwent pterional craniotomy

(3) Patients who underwent frontotemporal reconstruction with a Medpor ${ }^{\circledR}$ temporal implant

(4) Patients who underwent postoperative evaluation, including clinical outcome, esthetic outcome, and radiological examination, at 3 months postoperatively

Exclusion criteria for the present study were as follows:

(1) Diagnosis of with ruptured aneurysm

(2) Neurological deficits

(3) Bilateral pterional craniotomy

(4) Procedures affecting the thickness of soft tissue of the temporal area on the affected or nonaffected side

(5) No postoperative evaluation (because the patient did not visit the outpatient clinic of the Department of Neurosurgery of our medical institution at 3 months postoperatively)

The present study was approved by the Institutional Review Board (IRB) of our medical institution (IRB approval number: OC17RESI0159). The informed consent requirement was waived due to the retrospective nature of the study. All data was analyzed anonymously and according to the principles in the Declaration of Helsinki (1975, revised in 2008).

A total of 92 patients were included in this study and we evaluated the clinical outcome, degree of esthetic satisfaction, and radiologic data in these cases.

2.2. Surgical Technique. After completion of the cranial operation using the pterional approach, which was performed as described by Spetzler and Lee [21], the bone flap was secured to the skull with metallic plates and screws (Figure 1). The prefabricated high-density polyethylene (HDPE) implant (Medpor; Stryker, Kalamazoo, MI) was tailored with heavy scissors to fit the dimensions and contours of the defect accurately. Once positioned correctly, the Medpor ${ }^{\circledR}$ implant was secured in place with metallic screws (Figure 2). The temporalis muscle was then suspended and the soft tissue was approximated (Figure 3).

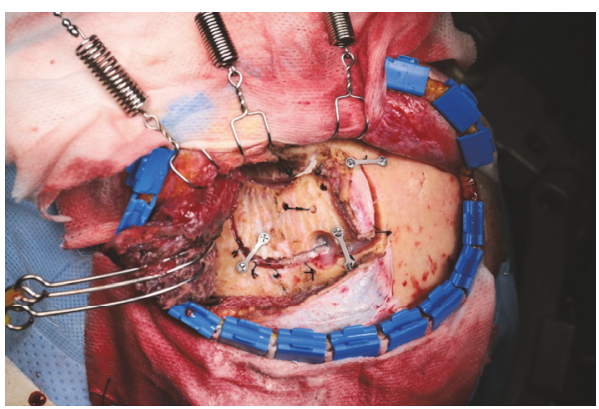

FIGURE 1: Intraoperative photograph after pterional craniotomy. The bone flap was secured with metallic plates and screws under the elevated temporalis muscle.

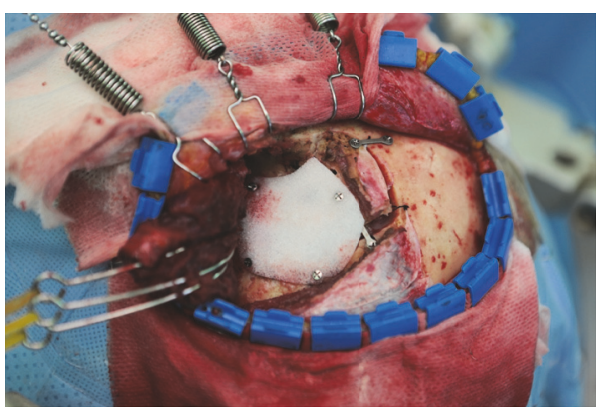

FIGURE 2: Intraoperative photograph after Medpor ${ }^{\circledR}$ implant insertion. The Medpor ${ }^{\circledR}$ implant was applied to the secured bone flap and fixed with metallic screws.

\subsection{Quantitative Measurement of the Thickness and Volume of} Temporalis Muscle. The thicknesses of the temporalis muscle and Medpor ${ }^{\circledR}$ implant were measured on brain CT axial images. The perpendicular line from the sphenoid greater wing to the outer margin of the temporalis muscle was defined as the thickness of the temporalis muscle. The thickness of the temporalis muscle reconstructed with a Medpor ${ }^{\circledR}$ implant was measured in the same manner from the sphenoid greater wing to the outer margin of the temporalis muscle, including the Medpor ${ }^{\circledR}$ implant (Figure 4). The volumes of the temporalis muscle and Medpor ${ }^{\circledR}$ implant were measured as described previously [22], using the public domain, Javabased image processing software package ImageJ, developed at the National Institutes of Health (NIH, Bethesda, MD) (Figure 5) [23].

2.4. Esthetic Outcomes. Esthetic results, from both the surgeon's and the patient's perspectives, were analyzed and classified as excellent, good, regular, or poor using a predetermined scale.

2.5. Statistical Analysis. Statistical analyses were performed using SPSS for Windows software (ver. 18.0; SPSS Inc., Chicago, IL). All data are expressed as the average \pm standard deviation (SD). The paired $t$-test was used to compare the ratios of thickness and volume between the affected and 


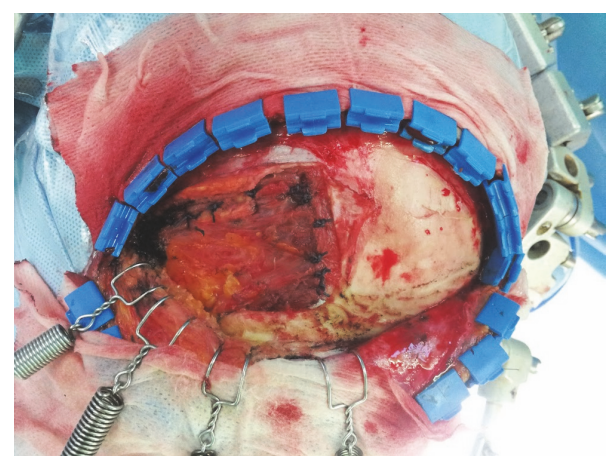

FIGURE 3: Intraoperative photograph after suspension of temporalis muscle. After application of the Medpor ${ }^{\circledR}$ implant to the bone flap, the elevated temporalis muscle was approximated to the cutting end of the temporalis muscle attached to the bone.

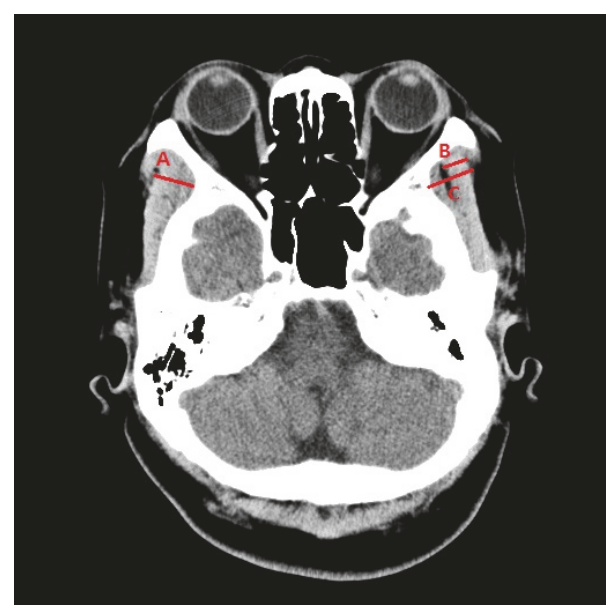

FIGURE 4: Thickness of the temporalis muscle and Medpor ${ }^{\circledR}$ implant. (A) Temporalis muscle thickness of the nonaffected side. (B) Temporalis muscle thickness of the affected side. (C) Temporalis muscle thickness of the nonaffected side with Medpor ${ }^{\circledR}$.

nonaffected sides. In all analyses, $P<0.05$ was taken to indicate statistical significance.

\section{Results}

The mean ratio of temporalis muscle thickness between the affected and nonaffected sides was $0.61 \pm 0.16$. The mean ratio of reconstructed temporalis muscle and Medpor ${ }^{\circledR}$ thickness between the affected and nonaffected sides was $1.15 \pm 0.02$. The mean ratio of temporalis muscle volume between the affected and nonaffected sides was $0.67 \pm 0.02$. The mean ratio of reconstructed temporalis muscle and Medpor ${ }^{\circledR}$ volume between the affected and nonaffected sides was $1.18 \pm 0.02$. The thickness and volume of the temporalis muscle were significantly increased after reconstruction with the Medpor ${ }^{\circledR}$ implant (both, $P \leq 0.001$ ) (Table 1 and Figure 6). Overall patient satisfaction (excellent and good) was observed in 83 of 92 patients $(90.2 \%)$, and there were no additional complications.
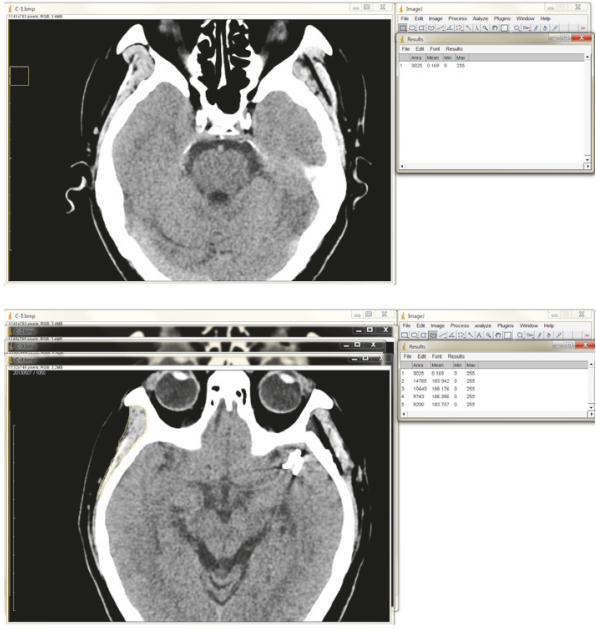

FIGURE 5: Calculation of temporalis muscle volume using ImageJ. (Top) A square with the length of the reduced scale $(1 \mathrm{~cm})$ in an axial section of a computed tomography (CT) image was drawn. The number of pixels inside the square per unit area $\left(1 \mathrm{~cm}^{2}\right)$ was calculated to be 3025 using the rectangular selection tool. (Bottom) A curved line was drawn along the margin of the temporalis muscle using the freehand selection tool. The number of pixels inside the region of interest was determined.

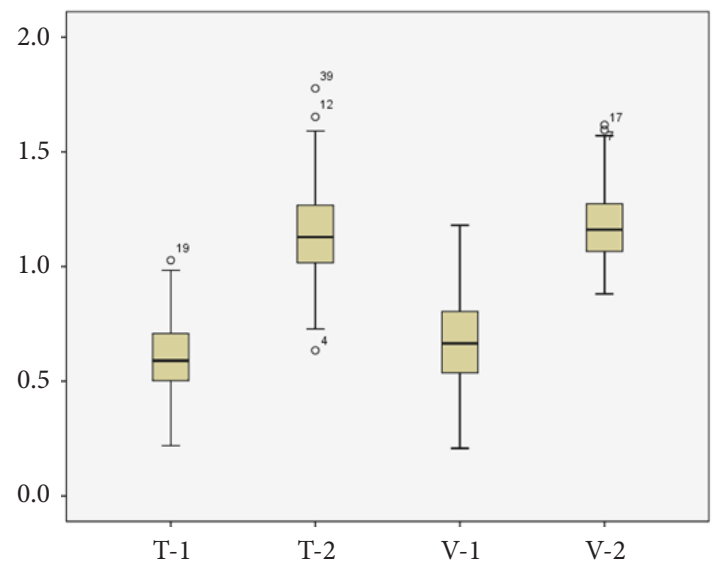

FIGURE 6: Box plot showing the ratio between the thickness and volume of the affected and nonaffected temporalis muscle. T-1, temporalis muscle thickness ratio $(0.61 \pm 0.16)$; $\mathrm{T}-2$, reconstructed temporalis muscle thickness ratio $(1.15 \pm 0.02) ; \mathrm{V}-1$, temporalis muscle volume ratio $(0.67 \pm 0.02)$; $\mathrm{V}-2$, reconstructed temporalis muscle volume ratio $(1.18 \pm 0.02), P \leq 0.001$.

\section{Discussion}

Temporal hollowing is a contour irregularity in the frontotemporal area, which commonly develops following surgical dissection in the temporal region, including via the intracranial access procedure $[24,25]$. Temporal hollowing can cause significant craniomaxillofacial asymmetry, esthetic deformity, and serious cosmetic concern in patients, even when there is an excellent postoperative functional outcome. The proposed mechanisms of temporal hollowing include devascularization, denervation, or disruption of the fat pads 
TABLE 1: Baseline characteristics of temporal lesions.

\begin{tabular}{lcc}
\hline & Average \pm SD & P-value \\
\hline Temporalis muscle thickness ratio & $0.61 \pm 0.16$ & $\leq 0.001$ \\
Reconstructed temporalis muscle thickness ratio & $1.15 \pm 0.02$ & $0.67 \pm 0.02$ \\
Temporalis muscle volume ratio & $1.18 \pm 0.02$ & $\leq 0.001$ \\
Reconstructed temporalis muscle volume ratio & \\
\hline
\end{tabular}

or temporalis muscle $[8,24,26]$. In pterional craniotomy using the "interfascial temporalis flap" technique, the intermediate temporal fat pad is split vertically to create two separate composite flaps. The anteriorly reflected flap includes skin, superficial temporal fascia, partial superficial layer of the deep temporal fascia, partial intermediate temporal fat pad, and partial deep layer of the deep temporal fascia. The posteroinferiorly reflected flap includes the temporalis muscle, deep temporal fat pad, partial deep layer of the deep temporal fascia, and partial intermediate fat pad [25]. Use of the myocutaneous flap technique has been reported to avoid fat pad dissection. De Andrade et al. [27] reported that a myocutaneous flap group showed significantly lower levels of temporal hollowing compared to an interfascial temporalis group. However, this technique limits exposure of the anteroinferior temporal fossa.

Various therapeutic methods have been developed for reconstruction of temporal hollowing using both autograft and alloplast materials. Autologous bone has the advantages of being genetically identical to the patient, possessing the potential for growth and replacement of host cells, and a low incidence of infection [16, 28-32]. However, it causes donor site morbidity, graft resorption, and difficulties with contouring, and additional time is required for harvesting of the graft $[31,33]$. Moreover, this technique cannot adequately restore deficient soft tissue [24]. Autologous fat grafting can also be used for correction of volume loss of the temporal lesion [34-37]. It is characterized by minimal donor site morbidity and minimal postoperative pain, but isolated use of a fat graft is inadequate for reconstruction of temporal depression because of the variable degree of graft absorption and the subsequent need for serial grafting. Adjuvant techniques combined with alloplastic grafts would be effective for temporal hollowing [24].

Alloplastic materials have emerged for replacement of autologous tissue; these are biocompatible with the surrounding bone and soft tissue, durable over time, easily molded, and associated with low donor site morbidity [33, 38]. Methyl methacrylate, an acrylic-based resin, is biocompatible, inelastic, strong, and readily available [33]. However, it is an inert material and injures local tissues due to the release of heat during shaping of the material. There is also an elevated risk of infection when it is applied to contaminated areas, such as the paranasal sinuses, and in cases of prior infection [39]. Hydroxyapatite, the primary mineral component of bone, has excellent tissue compatibility and a high capacity for osteoconduction and osteointegration. However, it has a high rate of infection and cannot bear significant loads [33, 39].

Porous polyethylene is commonly used for facial augmentation or reconstruction of various defects in the facial skeleton. Polyethylene is composed of straight-chain aliphatic hydrocarbons, is inert, and causes little tissue reactivity [40]. The vascular and tissue ingrowth of HDPE caused by the porous nature of the materials contributes to longterm stability and resistance to infection. There is also little evidence of implant degradation or resorption $[29,40]$.

Liu et al. [29] reported a surgical technique using Medpor ${ }^{\circledR}$ porous polyethylene implants in 611 standard cranial and skull base procedures, including treatment for temporal hollowing after pterional craniotomy. They noted satisfactory compensation of temporalis muscle atrophy and no implantrelated complications. Rapidis et al. [41] discussed the use of a prefabricated porous HDPE temporal implant after temporalis myofascial flap (TMF) transposition in a retrospective review of 21 patients. Long-term functional and esthetic results were shown to be stable even in patients receiving postoperative radiotherapy. Mericli et al. [24] presented four patients treated for temporal hollowing correction using HDPE after either craniotomy or extirpative surgery for neoplasm. They also described subtypes of temporal defects treated by appropriate reconstruction methods and reported that HDPE was a safe, well-studied, and easily handled biomaterial for recovery of temporal hollowing.

As outlined above, there have been several reports regarding reconstruction techniques using Medpor ${ }^{\circledR}$ implants following the pterional approach. However, there have been few studies regarding the severity of temporal hollowing or the effects of reconstruction using Medpor ${ }^{\circledR}$ implants based on objective measurements.

This study demonstrated the extent of temporal hollowing after pterional craniotomy, as well as the postoperative outcomes of frontotemporal reconstructions done using Medpor ${ }^{\circledR}$ implants, based on the objective values in 92 patients. The temporalis muscle was atrophied to about 39\% and 33\% in thickness and volume, respectively, after application of the pterional approach. The temporal hollowing was significantly ameliorated after reconstruction using Medpor ${ }^{\circledR}$ implants, with increases of about $15 \%$ and $18 \%$ in thickness and volume, respectively, compared to the nonaffected side. Overreconstruction of the affected side may be due to postoperative changes, such as inflammation and scarring between the injured periosteum and Medpor ${ }^{\circledR}$ implant or between the Medpor ${ }^{\circledR}$ implant and temporalis muscle layer.

This study had several limitations. First, it was retrospective in design. Second, it compared the thickness and volume of temporalis muscle between the affected and nonaffected sides but did not consider the possibility of temporalis muscle asymmetry between the two sides. Third, only deep soft tissue including the temporalis muscle was compared. The superficial soft tissue layer outside the temporalis muscle 
was not included in the measurement of temporal hollowing because this tissue could be influenced by multiple factors, such as inflammation, swelling, and scarring. Further studies to determine the soft tissue factors affecting temporal hollowing are required.

\section{Conclusions}

Significant temporalis muscle atrophy affected postoperative temporal hollowing following pterional craniotomy. Reconstruction of frontotemporal lesions using Medpor ${ }^{\circledR}$ temporal implants after the pterional approach effectively improved temporal hollowing without additional complications.

\section{Data Availability}

The [supplemental] data used to support the findings of this study are included within the supplementary information file.

\section{Disclosure}

This paper was presented as a poster at the $35^{\text {th }}$ Annual Spring Meeting of the Korean Neurosurgical Society, April 13-15, 2017.

\section{Conflicts of Interest}

The authors declare that they have no conflicts of interest.

\section{Supplementary Materials}

S1 Table. The ratio of temporalis muscle thickness and volume of 92 patients. (Supplementary Materials)

\section{References}

[1] F. Chaddad-Neto, J. M. C. Filho, H. L. Dória-Netto, M. H. Faria, G. C. Ribas, and E. Oliveira, "The pterional craniotomy: Tips and tricks," Arquivos de Neuro-Psiquiatria, vol. 70, no. 9, pp. 727732, 2012.

[2] M. G. Yaşargil, "A legacy of microneurosurgery: Memoirs, lessons, and axioms," Neurosurgery, vol. 45, no. 5, pp. 1025-1091, 1999.

[3] M. G. Yasargil, K. Kasdaglis, K. K. Jain, and H. P. Weber, "Anatomical observations of the subarachnoid cisterns of the brain during surgery," Journal of Neurosurgery, vol. 44, no. 3, pp. 298-302, 1976.

[4] N. McLaughlin, A. Cutler, and N. A. Martin, "Technical nuances of temporal muscle dissection and reconstruction for the pterional keyhole craniotomy ; Technical note," Journal of Neurosurgery, vol. 118, no. 2, pp. 309-314, 2013.

[5] M. G. Yasargil, M. V. Reichman, and S. Kubik, "Preservation of the frontotemporal branch of the facial nerve using the interfascial temporalis flap for pterional craniotomy. Technical article," Journal of Neurosurgery, vol. 67, no. 3, pp. 463-466, 1987.

[6] E. G. Figueiredo, P. Deshmukh, J. M. Zabramski, M. C. Preul, N. R. Crawford, and R. F. Spetzler, "The Pterional-transsylvian Approach: An Analytical Study," Operative Neurosurgery, vol. 59, pp. ONS-263-ONS-269, 2006.
[7] E. G. Figueiredo, A. M. P. Oliveira, J. P. P. Plese, and M. J. Teixeira, "Perspective of the frontolateral craniotomies," Arquivos de Neuro-Psiquiatria, vol. 68, no. 3, pp. 430-432, 2010.

[8] S. Kim and D. B. Matic, "The anatomy of temporal hollowing: The superficial temporal fat pad," The Journal of Craniofacial Surgery, vol. 16, no. 5, pp. 760-763, 2005.

[9] M. Lacey, O. Antonyshyn, and J. H. MacGregor, “Temporal contour deformity after coronal flap elevation: An anatomical study," The Journal of Craniofacial Surgery, vol. 5, no. 4, pp. 223227, 1994.

[10] D. B. Matic and S. Kim, "Temporal hollowing following coronal incision: A prospective, randomized, controlled trial," Plastic and Reconstructive Surgery, vol. 121, no. 6, 2008.

[11] J. A. Persing, P. L. Mayer, H. M. Spinelli, L. Miller, and G. R. Criscuolo, "Prevention of "Temporal Hollowing" After Frontoorbital Advancement for Craniosynostosis," The Journal of Craniofacial Surgery, vol. 5, no. 4, pp. 271-274, 1994.

[12] S. Zhong, G. J. Huang, S. M. Susarla, E. W. Swanson, J. Huang, and C. R. Gordon, "Quantitative analysis of dual-purpose, patient-specific craniofacial implants for correction of temporal deformity," Neurosurgery, vol. 11, pp. 220-229, 2015.

[13] J. M. Caplan, K. Papadimitriou, W. Yang et al., “The minipterional craniotomy for anterior circulation aneurysms: Initial experience with 72 patients," Neurosurgery, vol. 10, pp. 200-206, 2014.

[14] E. G. Figueiredo, P. Deshmukh, P. Nakaji et al., "THE MINIPTERIONAL CRANIOTOMY," Operative Neurosurgery, vol. 61, pp. 256-265, 2007.

[15] E. Kim and J. B. Delashaw Jr., "Osteoplastic pterional craniotomy revisited," Neurosurgery, vol. 68, no. 1, pp. ons125ons129, 2011.

[16] F. D. Burstein, S. R. Cohen, R. Hudgins, and W. Boydston, "The Use of Porous Granular Hydroxyapatite in Secondary Orbitocranial Reconstruction," Plastic \&amp Reconstructive Surgery, vol. 100, no. Supplement 1, pp. 869-874, 1997.

[17] L. K. Cheung, N. Samman, and H. Tideman, "The use of mouldable acrylic for restoration of the temporalis flap donor site," Journal of Cranio-Maxillo-Facial Surgery, vol. 22, no. 6, pp. 338-341, 1994.

[18] A. K. Gosain, "Hydroxyapatite cement paste cranioplasty for the treatment of temporal hollowing after cranial vault remodeling in a growing child," The Journal of Craniofacial Surgery, vol. 8, no. 6, pp. 506-511, 1997.

[19] C. H. McNichols, D. A. Hatef, P. Cole, L. H. Hollier, and J. F. Thornton, "Contemporary techniques for the correction of temporal hollowing: Augmentation temporoplasty with the classic dermal fat graft," The Journal of Craniofacial Surgery, vol. 23, no. 3, pp. e234-e238, 2012.

[20] K. Movassaghi, J. Ver Halen, P. Ganchi, S. Amin-Hanjani, J. Mesa, and M. J. Yaremchuk, "Cranioplasty with subcutaneously preserved autologous bone grafts," Plastic and Reconstructive Surgery, vol. 117, no. 1, pp. 202-206, 2006.

[21] R. F. Spetzler and K. S. Lee, "Reconstruction of the temporalis muscle for the pterional craniotomy: Technical note," Journal of Neurosurgery, vol. 73, no. 4, pp. 636-637, 1990.

[22] E. Y. Rha, J. M. Kim, and G. Yoo, "Volume Measurement of Various Tissues Using the Image J Software," The Journal of Craniofacial Surgery, vol. 26, no. 6, pp. e505-e506, 2015.

[23] C. A. Schneider, W. S. Rasband, and K. W. Eliceiri, "NIH Image to ImageJ: 25 years of image analysis," Nature Methods, vol. 9, no. 7, pp. 671-675, 2012. 
[24] A. F. Mericli and T. J. Gampper, "Treatment of postsurgical temporal hollowing with high-density porous polyethylene," The Journal of Craniofacial Surgery, vol. 25, no. 2, pp. 563-567, 2014.

[25] E. E. Vaca, C. A. Purnell, A. K. Gosain, and M. S. Alghoul, "Postoperative temporal hollowing: Is there a surgical approach that prevents this complication? A systematic review and anatomic illustration," Journal of Plastic, Reconstructive \& Aesthetic Surgery, vol. 70, no. 3, pp. 401-415, 2017.

[26] P. A. S. Kadri and O. Al-Mefty, "The anatomical basis for surgical preservation of temporal muscle," Journal of Neurosurgery, vol. 100, no. 3, pp. 517-522, 2004.

[27] F. C. De Andrade Jr., F. C. De Andrade, C. M. De Araujo Filho, and J. Carcagnolo Filho, "Dysfunction of the temporalis muscle after pterional craniotomy for intracranial aneurysms. Comparative, prospective and randomized study of one flap versus two flaps dieresis," Arquivos de Neuro-Psiquiatria, vol. 56, no. 2, pp. 200-205, 1998.

[28] F. D. Burstein, S. R. Cohen, R. Hudgins, W. Boydston, and C. Simms, "The use of hydroxyapatite cement in secondary craniofacial reconstruction," Plastic and Reconstructive Surgery, vol. 104, no. 5, pp. 1270-1275, 1999.

[29] J. K. Liu, O. N. Gottfried, C. D. Cole, W. R. Dougherty, and W. T. Couldwell, "Porous polyethylene implant for cranioplasty and skull base reconstruction., Neurosurgical Focus, vol. 16, no. 3, p. ECP1, 2004.

[30] H. B. Gladstone, M. W. McDermott, and D. D. Cooke, "Implants for cranioplasty," Otolaryngologic Clinics of North America, vol. 28, no. 2, pp. 381-400, 1995.

[31] A. Moreira-Gonzalez, I. T. Jackson, T. Miyawaki, K. Barakat, and V. DiNick, "Clinical Outcome in Cranioplasty: Critical Review in Long-Term Follow-Up," The Journal of Craniofacial Surgery, vol. 14, no. 2, pp. 144-153, 2003.

[32] Y. S. Kim, H. S. Yi, H. K. Kim, and Y. S. Han, "Effectiveness of Temporal Augmentation Using a Calvarial Onlay Graft during Pterional Craniotomy," Archives of Plastic Surgery, vol. 43, no. 2, pp. 204-209, 2016.

[33] Y. R. Cho and A. K. Gosain, "Biomaterials in craniofacial reconstruction," Clinics in Plastic Surgery, vol. 31, no. 3, pp. 377385, 2004.

[34] R. Haug, "Facial recontouring with lipostructure," Journal of Oral and Maxillofacial Surgery, vol. 55, no. 9, pp. 1034-1035, 1997.

[35] A. Chajchir, I. Benzaquen, and S. Fredricks, "Fat-Grafting Injection for Soft-Tissue Augmentation," Plastic and Reconstructive Surgery, vol. 84, no. 6, p. 935, 1989.

[36] Y. Xie, D. N. Zheng, Q. F. Li et al., "An integrated fat grafting technique for cosmetic facial contouring," Journal of Plastic, Reconstructive \& Aesthetic Surgery, vol. 63, no. 2, pp. 270-276, 2010.

[37] R.-L. Huang, Y. Xie, W. Wang et al., "Anatomical study of temporal fat compartments and its clinical application for temporal fat grafting," Aesthetic Surgery Journal, vol. 37, no. 8, pp. 855-862, 2017.

[38] A. K. Gosain and J. A. Persing, "Biomaterials in the Face," The Journal of Craniofacial Surgery, vol. 10, no. 5, pp. 404-414, 1999.

[39] P. N. Manson, W. A. Crawley, J. E. Hoopes, and S. A. Wolfe, "Frontal cranioplasty: Risk factors and choice of cranial vault reconstructive material," Plastic and Reconstructive Surgery, vol. 77, no. 6, pp. 888-900, 1986.

[40] C. A. Homsy, "Bio-Compatibility in selection of materials for implantation," Journal of Biomedical Materials Research Part B: Applied Biomaterials, vol. 4, no. 3, pp. 341-356, 1970.
[41] A. D. Rapidis and T. A. Day, "The use of temporal polyethylene implant after temporalis myofascial flap transposition: Clinical and radiographic results from its use in 21 patients," Journal of Oral and Maxillofacial Surgery, vol. 64, no. 1, pp. 12-22, 2006. 


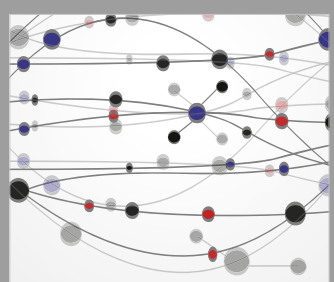

The Scientific World Journal
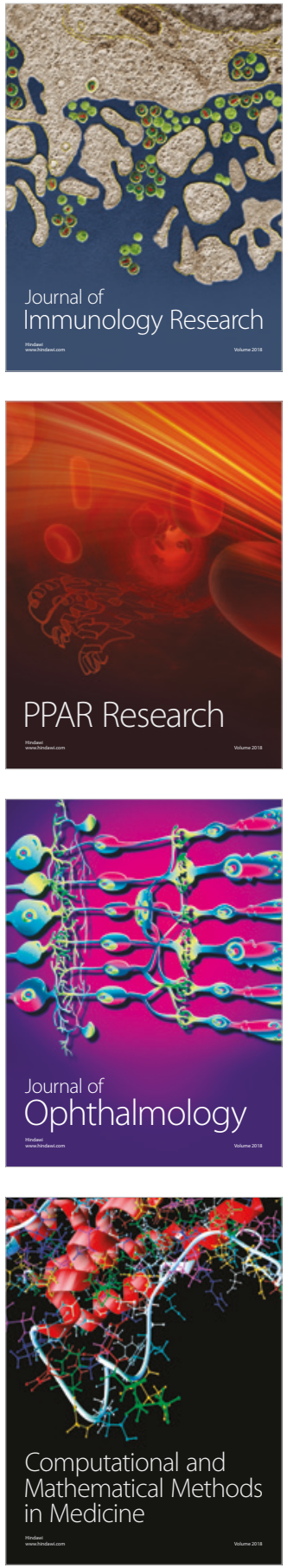

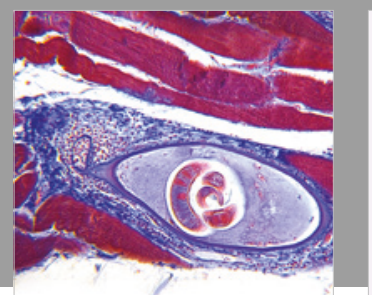

Gastroenterology Research and Practice

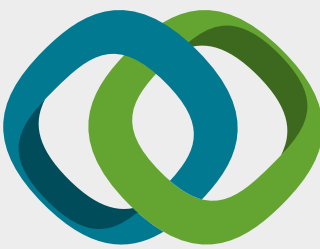

\section{Hindawi}

Submit your manuscripts at

www.hindawi.com
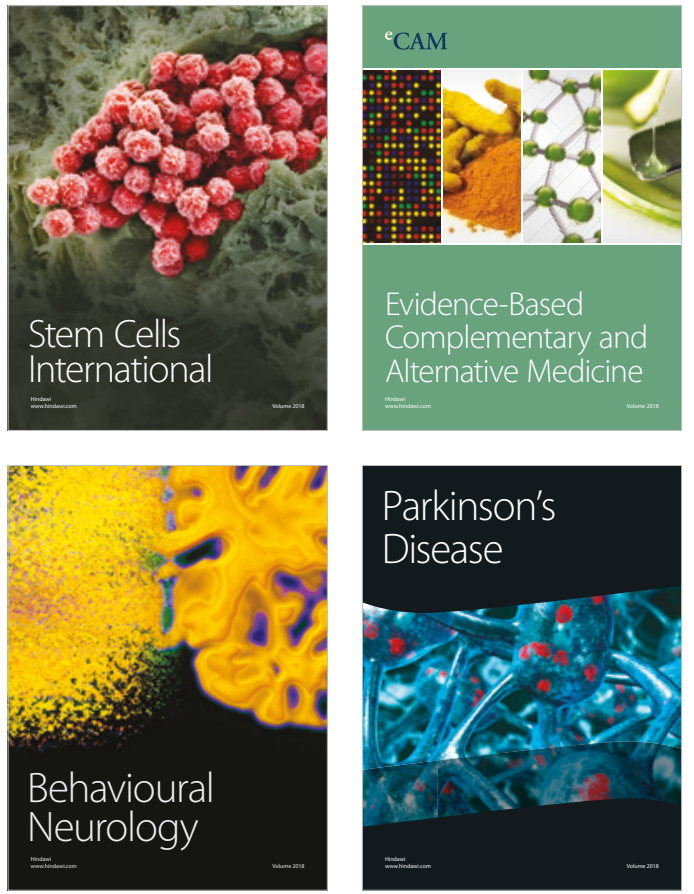

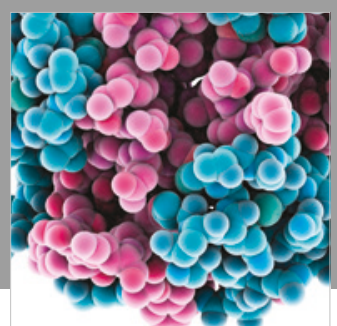

ournal of

Diabetes Research

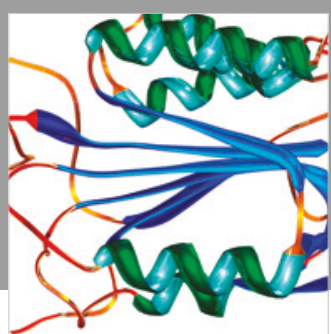

Disease Markers
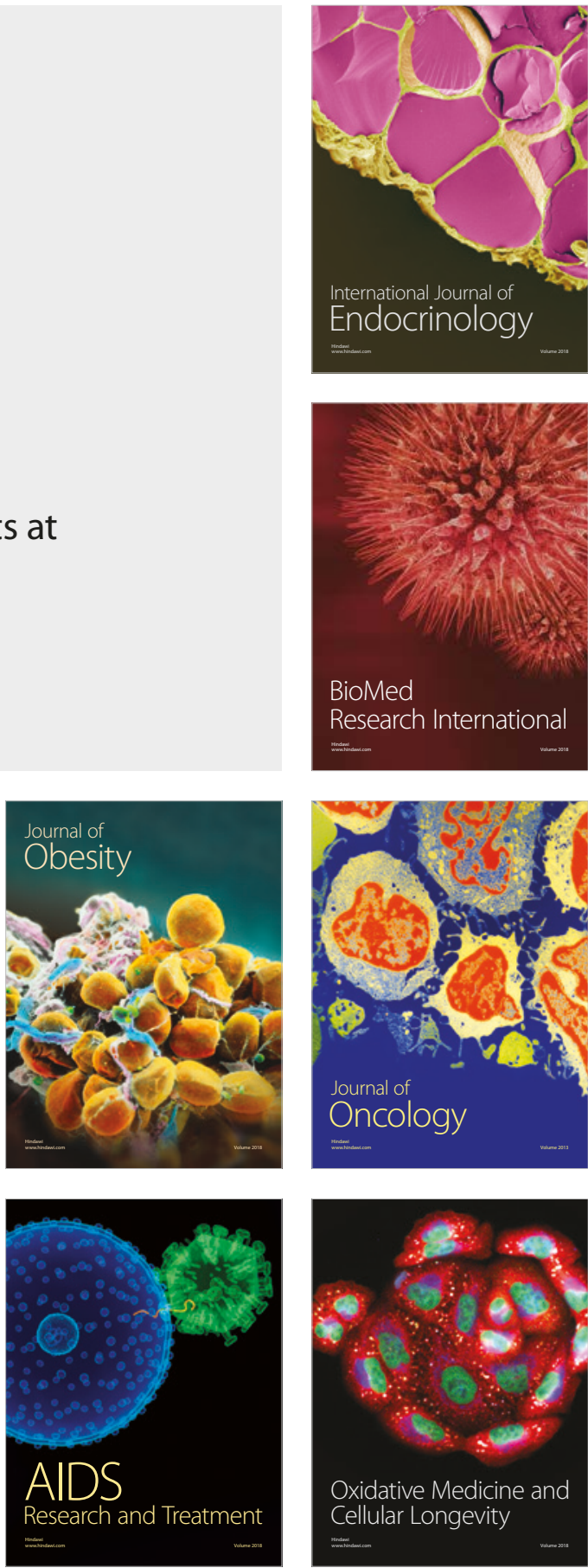